\title{
BIO-ECONOMY BASED BUSINESS MODELS FOR THE FOREST SECTOR - A SYSTEMATIC LITERATURE REVIEW
}

Wiebke REIM, Department of Entrepreneurship and Innovation, Luleå University of Technology, 97187 Luleå, Sweden, wiebke.reim@ltu.se (corresponding author)

David SJÖDIN, Department of Entrepreneurship and Innovation, Luleå University of Technology, 97187 Luleå, Sweden, david.sjodin@1tu.se

Vinit PARIDA, Department of Entrepreneurship and Innovation, Luleå University of Technology, 97187 Luleå, Sweden, vinit.parida@1tu.se

Ulrika ROVA, Department of Biochemical Process Engineering, Luleå University of Technology, 97187 Luleå, Sweden, ulrika.rova@ltu.se

Paul CHRISTAKOPOULOS, Department of Biochemical Process Engineering, Luleå University of Technology, 97187 Luleå, Sweden, paul.christakopoulos@1tu.se

The shift towards a bio-economy is one of the main focus areas of political initiatives aiming for a society relying on renewable biological sources while achieving economic growth. The forest sector is expected to contribute significantly to the development of the bio-economy which at the same time support rural development by creating new markets for advanced forest based products. However there is a need to focus more on the economic feasibility of such initiatives. Literature on bio-economy often implicitly addresses certain aspects connected to business models but is lacking a holistic perspective on the role of business models for the successful shift towards a bio-economy in the forest sector. Therefore, the purpose of this paper is to conduct a systematic literature review about bio-economy business models in the forest sector to advance the understanding about increased and sufficient value generation necessary to persuade a shift towards bio-economy. This paper is based on a systematic review of 42 scientific journal articles and book chapters on forest based bio-economy. The first result of the article is a structured aggregation of the existing bioeconomy business models including the maturity and potential for large scale application. The main implication of the paper is an overall framework on how to facilitate the commercialization of bio-economy based business models through an improved understanding of all elements of the business model canvas to reach market acceptance of innovative business models. Recommendations for future research are presented in the end of the paper.

Keywords: Bio-economy; Business models; Forest; Literature review

\section{INTRODUCTION}

The shift towards a bio-economy is one of the main focus areas of political initiatives aiming for a society relying on renewable biological sources while achieving economic growth (Kleinschmit et al., 2014). The forest sector is expected to contribute significantly to the development of the bio-economy which at the same time support rural development by creating new markets for advanced forest based products (Brodin et al., 2017; Kleinschmit et al., 2014). In literature much attention has been devoted to technical aspects of new bio-based products as well as political strategies to support a shift towards bio-economy (Devappa et al., 2015; McCormick and Kautto, 2013). However there is a need to focus more on the economic feasibility of such initiatives and how new business models can be developed that enable the creation, delivery and capture of the high potential value from forest based bio-economy (Brodin, et al., 2015; Nabuurs, et al., 2014). Literature on bio-economy often implicitly addresses certain aspects connected to business models but is lacking a holistic perspective on the role of business models for the successful shift towards a bio-economy in the forest sector. Therefore, the purpose of this paper is to conduct a systematic literature review about bio-economy business models in the forest sector to advance the understanding about increased and sufficient value generation necessary to persuade a shift towards bio-economy. Utilizing the business model canvas (Osterwalder and Pigneur, 2010) that defines business models based on nine distinctive elements, literature on forest based business models for the bio-economy are analyzed. The results show that a lot of research covers topic related to the value proposition and key resources but that more research is needed about the customers and the customer relationship as well as cost structure and revenue stream.

Copyright (C) 2017 The Authors. Published by Aleksandras Stulginskis University. This is an open-access article distributed under the terms of the Creative Commons Attribution License (CC-BY 4.0), which permits unrestricted use, distribution, and reproduction in any medium, provided the original author and source are credited. 


\section{RESEARCH METHOD}

To advance the understanding of value generation in forest based bio-economy, the present study consists of a systematic literature review with a specific focus on research related to business models. According to Cook et al. (2007), systematic review differs from the general review in that it adopts a replicable, scientific and transparent process. This leads to developing collective insights based on theoretical synthesis of existing studies. In this way bias is limited and the legitimacy of data analysis is enhanced. These benefits lead to more reliable results that form the basis for drawing conclusions (Reim et al., 2015).

A literature search was conducted through the authors' library service using the Scopus database, one of the largest multidisciplinary abstract and citation databases of peer-reviewed literature. The database covers research from both major and minor publisher, including Elsevier, Emerald, Springer, and Wiley. Because this database covers peer-reviewed multi-disciplinary research studies, it was certain to find studies on bio-economy in the forest sector with a business or management focus. Several keywords were used to find relevant articles. The articles resulting from the initial search were refined through three steps which will be described as follows.

Step 1: Identifying publications and applying practical screening. The first step begins by setting certain practical screening criteria to ensure that only quality publications are included in the review. During the first search, therefore, conference articles, working papers, commentaries, and book review articles were excluded, aiming instead for a focus on journal publications as well as book chapters which is a common publication source in the field of bio-economy. No other quality criteria were used (e.g., journal rankings) for filtering; indeed, publications that cover the topic of bioeconomy may not always be published in highly ranked journals because it is still an emerging topic. The search also excluded articles that were not peer-reviewed or not written in English.

The chosen keywords for the literature search were supposed to cover the three areas of interest of the studies purpose. First, bio-economy, that also can be referred to as bioeconomy or bio-based economy. Either of them should be included in the literatures title, abstract or keywords. Second, to identify papers related to the forest sector, the keyword "forest" was used as this also would result in papers talking about forestry or forest industry. Finally, "business model" is used as the keyword for the third area covering both singular and plural form of the term. A search that asks for papers that include all three keywords resulted only in five papers. Therefore, searches combining two of the three keywords where performed. These three searches resulted after excluding doubles into 196 articles.

Step 2: Applying theoretical screening criteria. Because the focus of the study is on bio-economy business models in the forest sector, only conceptual or empirical studies that discussed business model aspects in the forest-based bioeconomy were included for further analysis. More specifically, all abstracts were read carefully and those that explicitly or implicitly discussed business model aspects or elements the full papers were retrieved. Similar, even studies that not explicitly used the term bio-economy but discussed new applications or materials part of the forest sector were included in the full analysis. After the screening, 36 articles were remaining.

Step 3: Final filtering and reference analysis. In this final stage, all 36 articles that met the inclusion criteria were downloaded and read in detail as a final analysis of the content. Each article's cited references were used as a secondary source of literature analysis. This led to the identification of six additional articles that were perceived to provide prominent contribution to the understanding of forest-based bio-economy business models. Thus, this systematic literature analysis is based on 42 articles. For the analysis of the articles, an open coding content analysis technique was utilized. When using this technique, notes and headings are written in the text based on their association with the research focus. While inductively reviewing the studies it was acknowledged that each study can contribute to several different headings. Thereafter, all headings were collected and discussed in relation to the nine business model canvas elements.

\section{RESEARCH RESULTS}

In the emerging research area of forest-based bio-economy a need for a holistic perspective about business models was identified because this would support the commercialization process of bio-based products in the forest sector (Brodin et al., 2017; Kajanus et al., 2014). The definition of a business model focuses on how value is created, delivered and captured. The business model canvas is an important tool to analyze business models based on nine elements (Osterwalder and Pigneur, 2010). These nine elements were utilized to analyze the existing literature on forest-based bio-economy. For each article included in the literature review it was analyzed which of the nine elements was addressed and in what way. By doing this it was possible to find out which elements are already well-addressed in literature and which need more attention in the future in order to develop complete business models for the forest-based bio-economy. In the following each element will be described through the findings from the literature. An overview of the results is presented in Figure 1.

\section{Value proposition}

The value proposition is well-covered in existing literature mainly by describing existing or potential offers related to bio-economy. This includes bio-energy (Cambro and Sowlati, 2014; Devappa et al., 2015; Nabuurs et al., 2014), bio-fuels (Ersson et al., 2013; Harfouche et al., 2014; McCormick and Kautto, 2013), bio-plastics (Brodin et al., 2017; Hansen, 2016; Harfouche et al., 2014; Iles and Martin, 2013), chemicals (Cambro and Sowlati, 2014; Hansen, 2016; Harfouche et al., 2014; Machani et al., 2014), pharmaceuticals (Devappa et al., 2015), nanocellulose (Hansen, 2016; Machani et al., 2014), tourism and services (Pelli et al., 2017). Much of this is related to the bio-refinery concept that is frequently studied and can lead to multiple outputs (Devappa et al., 2015; Gregg et al., 2017; Hansen, 2016; Jernström et al., 2017; Näyhä and Pesonen, 2012; 
Roberts and Nikolakis, 2014; Scoma et al., 2016). However, there is an ongoing debate about the value that is generated from the various outputs because many argue that the value added with bio-energy and bio-fuels is low (Nabuurs et al., 2014). Devappa et al. (2015) illustrate this by saying that wood that goes up in smoke is lost forever.

Considering the economic value generated through a shift towards bio-economy, new income streams emerge and especially for pulp and paper companies there is high potential to move away from stagnating markets with new business models (Jernström et al., 2017; Machani et al., 2014; Roberts and Nikolakis, 2014). However, many articles highlight the environmental value that bio-economy can create to support sustainability (Iles and Martin, 2013; Kleinschmit et al., 2014; Lunnan et al., 2008; McCormick and Kautto, 2013; Pelli et al., 2017). This also includes the role of the forest for water protection and bio-diversity (Brand and Singh, 2014; Nabuurs et al., 2014) as well as reduced landfill (MacFarlane, 2009). Many studies also address the high potential for social value generation through the bio-economy. Frequently mentioned are local employment (Cambro and Sowlati, 2014; Ersson et al., 2013; Harfouche et al., 2014; McCormick and Kautto, 2013), rural regeneration (Harfouche et al., 2014; Lunnan et al., 2008; Pelli et al., 2017; Scarlat et al., 2015), recreation (Nabuurs et al., 2014) and energy security (Cambro and Sowlati, 2014; Ersson et al., 2013; Lunnan et al., 2008). Overall, it can be summarized that the focus is on generating more value from a given volume considering economic, environmental and social value (Cambro and Sowlati, 2014; Devappa et al., 2015).

\section{Key activities}

The key activities in the forest-based bio-economy literature focus mainly on activities that are needed to succeed with a transition towards bio-economy. The need for more innovation is frequently mentioned (Brodin et al., 2017; Harfouche et al., 2014; Kleinschmit et al., 2014; McCormick and Kautto, 2013; Scarlat et al., 2015). An example is the need to further develop and improve the conversion process of various forest-based products and by-products (Cambro and Sowlati, 2014). To fulfill the goals of a bio- or circular-economy key activities are reuse and recycling (FranklinJohnson et al., 2016; Pan et al., 2015). Another connected key activity that is perceived as very challenging is logistics, especially when it comes to the reuse of by-products (MacFarlane, 2009; Näyhä and Pesonen, 2012). However, moving towards bio-economy requires also an internal transformation (Roberts and Nikolakis, 2014) that has to deal with a resisting culture in many traditional forest-based companies (Hansen, 2016). Another key activity that is crucial for success is to work with business model innovation and evaluation (Kajanus et al., 2014; Pelli, et al., 2017). In sum, literature focuses mainly on the activities relevant for a successful transition towards bio-economy.

\section{Key resources}

Literature that addresses key resources mainly takes up the different forest-based inputs in the production processes. The use of by-products from the traditional production processes in the forest industry has high potential for forest-based bio-economy (Devappa et al., 2015; Ersson et al., 2013; Pergola et al., 2017; Scarlat et al., 2015). Also foliage and forest waste that are traditional unexplored resources come into focus in the move towards bio-economy (Devappa et al., 2015; Gregg et al., 2017; Lunnan et al., 2008). There is also research on how to utilize waste within the bio-economy (Ersson et al., 2013; Gregg et al., 2017; Pan et al., 2015) and how urban wood can be used (MacFarlane, 2009). Furthermore, appropriate tree species are examined (Harfouche et al., 2014), specific tree types like poplar are studied (Devappa et al., 2015) as well as the improved utilization of coppice (Spinelli et al., 2017a; Spinelli et al., 2017b). A downside that is highlighted is the fear of fertility loss in the forests when also harvesting the parts that are usually left behind (Lunnan et al., 2008) but ash recycling is proposed as an alternative to solve this concern (Bohlin and Ross, 2002). Ever though little is mentioned on intellectual and human resources in the literature there is some research highlighting the large financial resources needed for commercialization of new forest-based products (Roberts and Nikolakis, 2014) and that the high risk related to commercialization leads to an unwillingness to invest (Jernström et al., 2017; Lunnan et al., 2008).

\section{Key partners}

A shift towards bio-economy will require an integrated system of many actors that can all be considered as key partners (Ersson et al., 2013). Policy makers have put the aim for a bio-based economy high on the agendas and are important key partners that are frequently addressed in the literature (Gregg et al., 2017; Kleinschmit et al., 2014; Lunnan et la., 2008; Scarlet et al., 2015). However, regulations can currently be seen as unreliable and there is a need to integrate public support with the whole value chain to reach the ambitious goals (Gregg et al., 2017; Jernström et al., 2017; Machani et al., 2014). Other key partners addressed in literature are research institutions (Kleinschmit et al., 2014; Näyhä and Pesonen, 2012) and suppliers (Cambero and Sowlati, 2014; Pan et al., 2015) that also include the forest owners (Bohlin and Ross, 2002; Lunnan et al., 2008). It is also highlighted that entrepreneurs and SMEs are crucial for the success of the bio-economy (Harfouche et al., 2014; Jernström et al., 2017) and that the joint effort that is needed can be facilitated by specific clusters that bring actors together (Näyhä and Pesonen, 2012). Finally, the citizen and overall society should be seen as a key partner that should be actively involved through responsive governance in the decision making on how to design the future bio-economy (Mastalathi, 2017).

\section{Customer relationship}

There is not much written explicitly about the customer relationship. But there is a need for reliable information to convince potential customers (Lynch et al., 2017; McCormick and Kautto, 2013) and this puts high demands on education and communication of the characteristics and benefits of the bio-economy (Iles and Martin, 2013; Pelli et al., 2017). The public acceptance will be crucial to success (Kleinschmit et al., 2014; Pan et al., 2015). One way to facilitate 
public acceptance and a good customer relationship is through eco-labeling as it assures the sustainable value of the products (Brand and Singh, 2014; Iles and Martin, 2013; Kleinschmit et al., 2014; Scarlet et al., 2015). However, forest companies are not known for sophisticated marketing and there is a lot of potential for improvements (Hansen, 2016).

\section{Channels}

Channels is the business model canvas element that is least addressed in literature. This might be the case because many studies talk about potential applications for bio-economy and have not yet reached to a stage where the distribution channels need special attention. Brodin et al. (2017) mention that it is important to consider the recyclability and reusability of products in order to design circular flows that includes the distribution to and from the customers (Pelli et al., 2017). Furthermore, Cambero and Sowlati (2014) include considerations about the availability and appropriateness of existing or new pipelines for new products connected to bio-economy into their study.

\section{Customer segments}

There are no studies that focus specifically on the types of customers in a forest-based bio-economy and the customer base is still somewhat uncertain (Jernström et al., 2017). However, there is a high potential to create new markets (Scarlat et al., 2015) and to attract new buyers (Jernström et al., 2017; Lunnan et al., 2008). Today's society is demanding natural, chemical-free and local products and wood-based products fit well for this (Hansen, 2016; Iles and Martin, 2013). Customers are willing to pay a little more for those environmentally friendly products (Lynch et al., 2017) but it is important to carefully consider the customer needs and market pull (Kajanus et la., 2014; Kleinschmit et al., 2014) and to tailor products and services to the potential bio-economy customer (Hansen, 2016).

\section{Cost structure}

The most frequent explicitly addressed cost in the literature is related to the cost for the biomass or feedstock (Lunnan et al., 2008; Pergola et al., 2017; Roberts and Nikolakis, 2014; Scarlat et al., 2015). It is crucial that biomass can be purchased at a competitive price, but this is challenged by the fact that there is competition with other uses of biomass (Cambero and Sowlati, 2014; Lunnan et al., 2008; Scarlat et al., 2015). Other costs that are mentioned are costs for the operation, production, logistics and distribution as well as capital costs (Cambero and Sowlati, 2014; Lunnan et al., 2008). Overall, it is highlighted that the production needs to be cost-efficient in order to be competitive (Brodin et al., 2017; Roberts and Nikolakis, 2014; Scarlet et al., 2015). However, Machani et al. (2014) stress the fact that there is too much focus on the traditional cost-saving instead of a focus on value creation.

\section{Revenue streams}

When it comes to revenues it is often stated that the products connected to bio-economy are not profitable yet and that they have to be as cheap as the non-bio-based product e.g. energy sources (Brodin et al., 2017; Lunnan et al., 2008; Scoma et al., 2016). Revenues are perceived as highly uncertain (Jernström et al., 2017; Roberts and Nikolakis, 2014) even though it needs to be stressed that the bio-economy offers many possibilities for new revenue streams to existing companies (Devappa et la., 2015). One type of revenue stream that actually is mentioned very often is subsidies (Hansen, 2016; Kleinschmit et al., 2014; Näyhä and Pesonen, 2012; Pan et al., 2015). These subsidies need to be carefully designed to focus on the long-term benefits (McCormick and Kautto, 2013). Subsidies together with taxes need to account for the socioeconomic benefits that are not included in the market price (Lunnan et al., 2008). However, it is important to show and aim for that products and services belonging to the forest-based bio-economy are profitable and not only depend on public support.

\section{CONCLUSION AND DISCUSSION}

Driven by the need for a more effective and sustainable way of using our planet's resources research on bioeconomy reveals high potential for balancing economic, social and environmental benefits (Cambero and Sowlati, 2014; Pelli et al., 2017). Still, most forest-based bio-economy offers are not profitable or exist only in a prototype version because commercialization is not feasible (Brodin et al., 2017; Lunnan et al., 2008). Therefore, this paper proposes that the business model concept is a useful tool to examine the status of all aspects relevant for commercialization and sufficient value generation. Through performing a systematic literature review on forest-based bio-economy papers that explicitly or implicitly address business models a previously lacking synthesis has been developed. Utilizing the business model canvas with its nine distinctive elements (Osterwalder and Pigneur, 2010) the analysis reveal which elements are already well covered in the literature and which need to be further studied to enable the development of complete business models for forest-based bio-economy.

The business model element that is extensively covered in literature is the value proposition. The high potential of bio-economy to generate economic, environmental and social value is well-addressed in the literature. Key activities especially for the transformation towards a bio-economy like the need for innovations are discussed in the existing literature. Similarly, key resources like by-products that got new awareness through the upcoming bio-economy are discussed but also the need for financial resources is mentioned. Details about the cost structure can also be found in literature even though detailed calculations are currently missing and need to be developed in the future. Most of the other business model elements show a clear need for future research because articles addressing them mainly pose questions that need to be answered or problems that need to be solved. Within key partners for example, policy institutions are the crucial main driver today but there is a huge need for more research on the total value chain that needs to be 


\section{Proceedings of the $8^{\text {th }}$ International Scientific Conference Rural Development 2017}

considered to succeed with the forest-based bio-economy. Comparable, the customer relationships are mainly covered by highlighting the need for reliable information and public acceptance. Eco-labeling is thus proposed as a way to enhance this process. Channels is the least addressed element even though new markets and customers are supposed to be attracted by the outcomes of the bio-economy. This connects to the customer segments that emphasize that the customer need has to be in focus and that products need to be tailored to bio-economy customers that might be willing to pay a little bit more if the products fulfill their demand for natural, chemical-free and local products. However, there is much research needed about potential customers in order to create profitable revenue streams in the future. Currently, many of the ongoing activities related to bio-economy are heavily depended on subsidies and it will be crucial for the future success of forestbased bio-economy products to reach economic profitability. Policy makers need to develop systems where the market price also accounts for the environmental and social value that the bio-economy generates. The business model concept emphasizes this holistic perspective on value generation and the importance to consider all the elements in order to develop appropriate business models.

\section{REFERENCES}

1. Bohlin, F., Roos, A. 2002. Wood fuel supply as a function of forest owner preferences and management styles. Biomass and Bioenergy, Vol. 22, Iss. 4, pp. 237-249.https://doi.org/10.1016/S0961-9534(02)00002-8

2. Brand, D., \& Singh, D. (2014). What is needed to make markets for ecosystem services a reality? In: Forests and Globalization: Challenges and Opportunities for Sustainable Development. Routledge.

3. Brodin, M., Vallejos, M., Opedal, M. T., Area, M. C., Chinga-Carrasco, G. 2017. Lignocellulosics as sustainable resources for production of bioplastics-a review. Journal of Cleaner Production, Vol. 20, pp. 646-664. https://doi.org/10.1016/j.jclepro.2017.05.209

4. Cambero, C., Sowlati, T. 2014. Assessment and optimization of forest biomass supply chains from economic, social and environmental perspectives-A review of literature. Renewable and Sustainable Energy Reviews, Vol. 36, pp. 62-73. https://doi.org/10.1016/j.rser.2014.04.041

5. Cook, D.J., Greengold, N.L, Ellrodt, A.G., Weingarten, S.R., 1997. The relation between systematic reviews and practice guideline. Annals of Internal Medicine, Vol. 127, Iss. 3, pp. 201-216. https://doi.org/10.7326/0003-4819-127-3-199708010-00006

6. Devappa, R. K., Rakshit, S. K., Dekker, R. F. 2015. Forest biorefinery: potential of poplar phytochemicals as value-added coproducts. Biotechnology advances, Vol. 33(6), pp. 681-716.https://doi.org/10.1016/j.biotechadv.2015.02.012

7. Ersson, C., Ammenberg, J., Eklund, M. 2013. Biofuels for transportation in 2030: feedstock and production plants in a Swedish county. Biofuels, Vol. 4(4), pp. 379-395. https://doi.org/10.4155/bfs.13.23

8. Franklin-Johnson, E., Figge, F., Canning, L. 2016. Resource duration as a managerial indicator for Circular Economy performance. Journal of Cleaner Production, Vol. 133, pp. 589-598. https://doi.org/10.1016/j.jclepro.2016.05.023

9. Gregg, J. S., Bolwig, S., Hansen, T., Solér, O., Ben Amer-Allam, S., Pladevall Viladecans, J., Fevolden, A. (2017). Value Chain Structures that Define European Cellulosic Ethanol Production. Sustainability, Vol. 9(1), pp. 118. https://doi.org/10.3390/su9010118

10. Harfouche, A., Khoury, S., Fabbrini, F., Mugnozza, G. S. 2015) Forest biotechnology advances to support global bioeconomy. Annals of Silvicultural Research, Vol. 38(2), pp. 42-50.

11. Iles, A., Martin, A. N. 2013. Expanding bioplastics production: sustainable business innovation in the chemical industry. Journal of Cleaner Production, Vol. 45, pp. 38-49. https://doi.org/10.1016/j.jclepro.2012.05.008

12. Jernström, E., Karvonen, V., Kässi, T., Kraslawski, A., Hallikas, J. 2017. The main factors affecting the entry of SMEs into biobased industry. Journal of Cleaner Production, Vol. 141, pp. 1-10. https://doi.org/10.1016/j.jclepro.2016.08.165

13. Kajanus, M., Iire, A., Eskelinen, T., Heinonen, M., Hansen, E. 2014. Business model design: new tools for business systems innovation. Scandinavian Journal of Forest Research, Vol. 29(6), pp. 603-614. https://doi.org/10.1080/02827581.2014.949301

14. Kleinschmit, D., Lindstad, B. H., Thorsen, B. J., Toppinen, A., Roos, A., Baardsen, S. 2014) Shades of green: a social scientific view on bioeconomy in the forest sector. Scandinavian Journal of Forest Research, Vol. 29(4), pp. 402-410. https://doi.org/10.1080/02827581.2014.921722

15. Lunnan, A., Vilkriste, L., Wilhelmsen, G., Mizaraite, D., Asikainen, A., Röser, D. 2008. Policy and economic aspects of forest energy utilisation. Sustainable use of forest biomass for energy: a synthesis with focus on the Baltic and Nordic region, Springer, Dordrecht, The Netherlands, pp. 197-234. https://doi.org/10.1007/978-1-4020-5054-1_8

16. Lynch, D. H., Klaassen, P., Broerse, J. E. 2017. Unraveling Dutch citizens' perceptions on the bio-based economy: The case of bioplastics, bio-jetfuels and small-scale bio-refineries. Industrial Crops and Products, Vol. 106, pp. 130-137. https://doi.org/10.1016/j.indcrop.2016.10.035

17. MacFarlane, D. W. 2009. Potential availability of urban wood biomass in Michigan: Implications for energy production, carbon sequestration and sustainable forest management in the USA. Biomass and Bioenergy, Vol. 33(4), pp. 628-634. https://doi.org/10.1016/j.biombioe.2008.10.004

18. Machani, M., Nourelfath, M., D'Amours, S. 2014. A Multi-level Decisional Approach to Design Integrated Forest Biorefinery Business Model for Pulp and Paper Companies Vol. 7. CIRRELT.

19. McCormick, K., Kautto, N. 2013. The bioeconomy in Europe: An overview. Sustainability, Vol. 5(6), pp. $2589-2608$. https://doi.org/10.3390/su5062589

20. Mustalahti, I. 2017. The responsive bioeconomy: The need for inclusion of citizens and environmental capability in the forest based bioeconomy. Journal of Cleaner Production., Vol. 172, pp. 3781-3790. https://doi.org/10.1016/j.jclepro.2017.06.132 
21. Nabuurs, G.J., Schelhaas, M.J., Hendriks, K., Hengeveld, G.M. 2014. Can European forests meet the demands of the bio-economy in the future? Wood supply alongside environmental services. In: Forests and Globalization: Challenges and Opportunities for Sustainable Development. Routledge.

22. Näyhä, A., Pesonen, H. L. 2012. Diffusion of forest biorefineries in Scandinavia and North America. Technological Forecasting and Social Change, Vol. 79(6), pp. 1111-1120. https://doi.org/10.1016/j.techfore.2012.01.006

23. Osterwalder, A., Pigneur, Y., 2010. Business model generation: a handbook for visionaries, game changers, and challengers. Wiley.

24. Pan, S. Y., Du, M. A., Huang, I. T., Liu, I. H., Chang, E. E., Chiang, P. C. 2015. Strategies on implementation of waste-to-energy (WTE) supply chain for circular economy system: a review. Journal of Cleaner Production, Vol. 108, pp. 409421.https://doi.org/10.1016/i.jclepro.2015.06.124

25. Pelli, P., Haapala, A., Pykäläinen, J. 2017. Services in the forest-based bioeconomy-analysis of European strategies. Scandinavian Journal of Forest Research, Vol. 32, Iss. 7, pp. 559-567. https://doi.org/10.1080/02827581.2017.1288826

26. Pergola, M., Gialdini, A., Celano, G., Basile, M., Caniani, D., Cozzi, M., ... \& Ventura, G. (2017). An environmental and economic analysis of the wood-pellet chain: two case studies in Southern Italy. The International Journal of Life Cycle Assessment, pp. 110.https://doi.org/10.1007/s11367-017-1374-Z

27. Reim, W., Parida, V., Örtqvist, D. 2015. Product-Service Systems (PSS) business models and tactics-a systematic literature review. Journal of Cleaner Production, Vol. 97, pp. 61-75. https://doi.org/10.1016/j.jclepro.2014.07.003

28. Roberts, D., Nikolakis, W. 2014. Thoughts on transforming the forest sector. The potential (and reality) of the bio-economy. In: Forests and Globalization: Challenges and Opportunities for Sustainable Development. Routledge.

29. Scarlat, N., Dallemand, J. F., Monforti-Ferrario, F., Nita, V. 2015. The role of biomass and bioenergy in a future bioeconomy: policies and facts. Environmental Development, Vol. 15, pp. 3-34.https://doi.org/10.1016/j.envdev.2015.03.006

30. Scoma, A., Rebecchi, S., Bertin, L., Fava, F. 2016. High impact biowastes from South European agro-industries as feedstock for second-generation biorefineries. Critical Reviews in Biotechnology, Vol. 36(1), pp. $175-189$. https://doi.org/10.3109/07388551.2014.947238

31. Spinelli, R., Magagnotti, N., Schweier, J. 2017a. Trends and Perspectives in Coppice Harvesting. Croatian Journal of Forest Engineering, Vol. 38(2), pp. 219-230.

32. Spinelli, R., Pari, L., Aminti, G., Magagnotti, N., Giovannelli, A. 2017b. Mortality, re-sprouting vigor and physiology of coppice stumps after mechanized cutting. Annals of Forest Science, Vol. 74(5), pp. 1-12. https://doi.org/10.1007/s13595-016-0604-Z 